\title{
Interpersonal Continuity of Care and Patient Satisfaction: A Critical Review
}

\author{
Jobn W. Saultz, MD \\ Waleed Albedaiwi, MD
}

Department of Family Medicine, School of Medicine, Oregon Health \& Science

University, Portland, Ore
Conflicts of interest: none reported

\section{CORRESPONDING AUTHOR}

John W. Saultz, MD

Department of Family Medicine

Oregon Health \& Science University

3181 SW Sam Jackson Park Road, FP

Portland, OR 97239-3098

saultz@ohsu.edu

\begin{abstract}
PURPOSE We wanted to review the medical literature regarding the relationship between interpersonal continuity of care and patient satisfaction and suggest future strategies for research on this topic.
\end{abstract}

METHODS A search of the MEDLINE database from 1966 through April 2002 was conducted to find articles focusing on interpersonal continuity of patient care. The resulting articles were screened to select those focusing on the relationship between interpersonal continuity in the doctor-patient relationship and patient satisfaction. These articles were systematically reviewed and analyzed for study method, measurement technique, and the quality of evidence.

RESULTS Thirty articles were found that addressed the relationship between interpersonal continuity and patient satisfaction with medical care. Twenty-two of these articles were reports of original research. Nineteen of the 22, including 4 clinical trials, reported significantly higher satisfaction when interpersonal continuity was present.

CONCLUSIONS Although the available literature reflects persistent methodologic problems, a consistent and significant positive relationship exists between interpersonal continuity of care and patient satisfaction. Future research in this area should address whether the same is true for all patients or only for those who seek ongoing relationships with physicians in primary care.

Ann Fam Med 2004;2:445-451. DOI: 10.1370/afm.91

\section{INTRODUCTION}

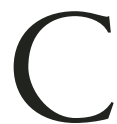
ontinuity of care is considered to be a core principle of family medicine $^{1,2}$ and primary care, ${ }^{3}$ but conclusive proof regarding its value has eluded primary care and health policy researchers. The first step in establishing this proof requires a specific definition of the most important elements of continuity. Previous authors have addressed different aspects of continuity and have proposed definitions with multiple dimensions. ${ }^{1,4-10}$ Recently, 3 of these dimensions were organized into a hierarchy ranging from the availability of accurate information from one health care encounter to another (informational continuity), through a pattern of health care utilization at a particular site of care (longitudinal continuity), to a personal doctor-patient relationship characterized by loyalty and trust (interpersonal continuity). ${ }^{11}$ For family physicians the concept of interpersonal continuity holds particular importance. ${ }^{12}$ Interpersonal continuity refers to a special type of longitudinal continuity in which an ongoing personal relationship between the patient and clinician is characterized by personal trust and responsibility. ${ }^{11}$ Changes in the American health care system during the past decade have made it increasingly difficult to establish such long-term trusting relationships between physicians and patients. ${ }^{13-19}$ Some authors have questioned whether a personal model of care is feasible, as health plans increasingly have required provider changes for economic reasons. ${ }^{20}$ As these changes occur, health policy planners are looking for evidence supporting the value of interpersonal continuity. 
Proving the value of interpersonal continuity would require us to show that outcomes or efficiency of care is somehow better when this attribute is present, but which clinical outcomes are most important to analyze and which are most amenable to methodologically sound analysis? If interpersonal continuity of care improves diabetes outcomes, does it necessarily follow that hypertension outcomes would also be improved? A logical starting point is to examine the degree to which interpersonal continuity improves patient satisfaction. Patient satisfaction is generally viewed as a desirable quality characteristic, ${ }^{3}$ and there are standardized techniques to measure satisfaction. ${ }^{21}$

Interpersonal continuity of care has been a common subject for review articles and philosophy articles in the medical literature. ${ }^{4-11,13,15,20,22-36}$ Several of these articles have concluded that interpersonal continuity improves patient satisfaction. . $7,24,30,33$ Others have suggested that a personal model of primary care may be an outdated concept. ${ }^{20,32}$ Nearly all of these reviews have commented on the inherent difficulty of conducting research in this area. This article describes our efforts to examine systematically the evidence regarding the association between interpersonal continuity and one aspect of care quality, the level of patient satisfaction.

\section{METHODS}

A search of the MEDLINE database from January 1, 1966, to April 30, 2002, was conducted using the medical subject heading "continuity of patient care," including all possible subheadings. Titles and reference citations of each of the resulting 2,424 citations in the English language articles were reviewed, and references were eliminated if they were letters to the editor, if they addressed health professions other than medicine, or if they clearly addressed only aspects of continuity other than interpersonal continuity. Excluding these articles left 379 citations that appeared to address interpersonal continuity as an attribute of the relationship between clinicians and patients in general medical care. Full-text copies of each of these articles were obtained and read in detail by the primary author In addition, the bibliographies of each of these articles were scanned to identify potential references that were missed by the MEDLINE search. The process of article review and exclusion has been previously described. ${ }^{11}$ This review process yielded 142 articles that directly related to the concept of interpersonal continuity. Forty-one were review or theory articles dealing with continuity of care in general. The remaining 101 were original research reports. All article citations were entered into a bibliographic database, and each was classified by study methods, primary research question(s), and how continuity was defined and measured. This classification process has been described. ${ }^{11}$

Seventy-eight of the 142 articles addressed the relationship between interpersonal continuity of care and the outcome, cost, or patient satisfaction with care. An analysis of the relationship between interpersonal continuity and care outcomes, including cost efficiency, will be the subject of a future paper. Thirty of the articles addressed the relationship between interpersonal continuity and

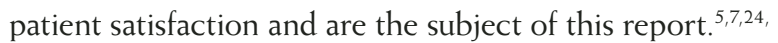
30,32,33,37-60 Twenty-two of these articles described original research on the subject, and the remaining 8 were reviews or related articles. The authors reviewed all 30 articles and systematically analyzed the 22 research articles to assess the significance and strength of this relationship. The goals of our analysis were to determine the quality of this evidence and to assess the methods used by the authors to examine the association.

We originally considered a meta-analysis of these data, but found it impossible because of substantial differences in how patient satisfaction was defined and measured among these articles. Thus, our analysis consisted of a systematic review of each article to determine the study method, the method by which interpersonal continuity was measured, the results of each study, and an assessment of the quality of evidence in each study. Quality was evaluated by determining the degree to which each study addressed 5 quality characteristics. We chose these 5 quality characteristics after reading the articles and discussing the project with colleagues. We then reviewed each study independently and assigned a score of 2, 1, or 0 for each quality characteristic that was met, partially met, or not met, respectively.

The 2 scores were averaged, and in those cases where the scores differed by more than 1 point (one score was 2 and the other 0 ), the article in question was reread by both authors and discussed to reach consensus. The 5 scores were totaled as a measure of the overall study quality. Rather than assigning a quality score based on study method, we sorted by study method to allow comparison of studies using different methods.

The 22 original research reports describe the results of 20 studies addressing the association between interpersonal continuity and patient satisfaction. These studies, as well as our qualitative assessment of the strength of evidence in each study, can be found in Appendix 1, which is available online as supplemental data at http:// www.annfammed.org/cgi/content/full/2/5/445/ DC1. Because each study was evaluated by the 5 criteria listed as questions heading the columns in the appendix, there were 100 quality scores assigned for the 20 studies. In 12 of the 100 cells, our quality score differed by more than 1 point. In 8 instances the areas of disagreement related to the criteria dealing with the 
measurement of satisfaction, primarily the degree to which subjective vs objective measures were used and whether the instruments had been previously validated. In all other cells the score is the average of our 2 scores. The sum of the scores for each criterion is listed in the last column. Table 1 lists further details about the setting and findings of each study, as well as the summative quality score from Appendix 1.

\section{RESULTS}

The relationship between continuity and patient satisfaction has been studied in 4 randomized trials that were identified in this review. All 4 found aspects of improved patient satisfaction in study groups with higher continuity of care. In the 1960s, Alpert and colleagues ${ }^{47,57}$ randomly assigned 931 low-income children to receive care in a comprehensive pediatric clinic or in a traditional pediatric walk-in clinic in Boston. The care of these 2 groups was compared at 2 and 4 years. Overall patient satisfaction was significantly higher in the intervention group, and mothers in this group also rated the ease of talking with the physician and clinic staff more highly. In a similar study, Becker and colleagues ${ }^{48,49}$ randomly assigned 125 low-income pediatric patients to either a clinic with continuity or a walk-in clinic and compared patient satisfaction 1 year later. Overall satisfaction was significantly higher in the continuity group, as was satisfaction with staff-patient interactions, clinic procedures, time spent with the physician, perceived quality of care, and confidence in the physicians' recommendations. A study by Wasson et al reported in $1984^{50}$ randomly assigned 776 men older than 55 years at a Veterans Administration (VA) clinic to either a continuity clinic or an outpatient clinic without continuity. Overall satisfaction and satisfaction with continuity of care, clinician thoroughness, and patient education were significantly higher in the continuity group after 2 years. In 1995 Rowley and colleagues ${ }^{58}$ reported a trial that randomly assigned 405 pregnant Australian women to receive care either from a continuity clinic staffed by 6 midwives or from a university teaching clinic without continuity. The intervention group had higher scores for 3 aspects of patient satisfaction: information giving, participation in decision making, and relationship with caregivers. None of these trials identified any aspects of satisfaction that were worse with continuity.

All of these trials were flawed by study methods that failed to isolate continuity as the only uncontrolled difference between the study groups. In 2 of the 4 trials, continuity of care was not measured in either the intervention or control group. ${ }^{48,49,58}$ Although the intervention groups were assigned to receive care in clinics that were designed to deliver care in an interpersonal continuity model, there is no evidence in these reports that the continuity was in fact better in these clinics. In the remaining 2 trials by Alpert et $\mathrm{al}^{47,57}$ and Wasson et $\mathrm{al}^{50}$ interpersonal continuity was measured by the percentage of patients who could name their physicians. Wasson et al also reported the usual provider continuity index (UPC) and the sequential continuity index (SECON) to show higher continuity scores in the intervention group. In spite of these flaws, all 4 clinical trials showed a significant improvement in patient satisfaction when intervention and control groups were compared.

Cohort studies have addressed the relationship between continuity and patient satisfaction among patients with hypertension in Seattle, ${ }^{42}$ obstetric patients in the United States, ${ }^{52}$ pediatric patients in an academic practice in Cleveland, ${ }^{53}$ and patients in a VA internal medicine clinic. ${ }^{46}$ All of these studies rated or measured the continuity of care and attempted to correlate the scores with patient satisfaction. Two of these cohort studies $^{52,53}$ did not find a significant association between continuity and patient satisfaction. Shear et $\mathrm{al}^{52}$ found higher satisfaction in patients receiving care with higher continuity in a family practice clinic compared with patients in an obstetrics-gynecology clinic, but the difference did not achieve statistical significance, and this study was confounded by differing providers and care models in the two settings. Breslau and Haug ${ }^{53}$ examined the change in continuity and satisfaction that occurred when 2 pediatricians moved their practices from the community into a teaching center. Although the patients were less likely to see their own physicians after the move, overall satisfaction did not change significantly. The remaining 2 cohort studies by Shortell et $\mathrm{al}^{42}$ and Smith ${ }^{46}$ both found a significant association between improved continuity and patient satisfaction. Shortell et al measured continuity in an unusual way by simply counting the number of clinicians seen. This measurement technique has been used only twice in studies addressing interpersonal continuity of care ${ }^{11}$ and may, in fact, be more of a measure of longitudinal continuity. Smith ${ }^{46}$ measured continuity of care in a small subset of the patients enrolled in their study, raising the question of whether interpersonal continuity truly differed in the 2 cohorts.

Most of the work relating continuity and satisfaction has been done in cross-sectional surveys or other correlational studies. Five of these 12 articles reported studies done in Europe $39,40,45,54,60$ and a sixth was done in both the United States and United Kingdom. ${ }^{55}$ Three of these studies compared British general practices using combined patient lists with those using personal lists. ${ }^{39,45,60}$ Combined list practices assign patients to the practice site, whereas personal list practices assign them to an individual physician. All 3 showed patient satisfaction advantages with personal lists, but 2 of the 3 studies did 
Table 1. Interpersonal Continuity and Patient Satisfaction

Study Method, Study, and Publication Date Setting

Findings*

Quality of Clinical trial

Wasson et al, $1984^{50}$

Becker et al, $1974^{48}$

Becker et al, $1974^{49}$

Alpert et al, 197057; Alpert et al, $1976^{47}$

Rowley et al, $1995^{58}$

Cohort, prospective Smith, $1995^{46}$

Shortell et al, $1977^{42}$

Breslau \& Haug, $1976^{53}$

Cohort, retrospective Shear et al, $1983^{52}$

Weyrauch, $1996^{43}$

Love et al, $2000^{4}$

\section{Correlation}

Breslau \& Mortimer, $1981^{37}$
Randomly assigned 776 men $>55$ y at a Veterans Administration (VA) clinic to either a continuity clinic or an outpatient clinic without continuity

Randomly assigned 125 low-income pediatric patients to either a clinic with continuity or a walk-in clinic. Both clinic staff and mothers were blinded to study design

Randomly assigned 931 low-income children from 750 families to receive care in a comprehensive pediatric clinic (252 families), a no-contact control group (257 families), and a control group that was interviewed along with the experimental group every $6 \mathrm{mo}$ (261 families)

Randomly assigned 405 pregnant Australian women to receive care from a continuity clinic staffed by 6 midwives and 409 women to a university teaching clinic without continuity

3 interdisciplinary care teams consisting of internal medicine faculty, residents, midlevel providers, pharmacists, and clinic staff were organized in a VA outpatient department. Approximately 2,500 patients were enrolled with each team. Satisfaction was measured before and after the change

106 patients with hypertension, 50 in private practices and 56 in a group model health maintenance organization (HMO) were studied to compare care settings for $2 y$

Children from 63 families receiving care from 2 pediatricians were evaluated before and after their physicians moved from a private office to a university clinic

59 pregnant women receiving perinatal care in a family practice clinic were compared with 101 women receiving care in an obstetric clinic. Continuity of care and patient satisfaction were measured and compared in both groups

Home interviews of 370 mothers of children with cystic fibrosis, cerebral palsy, myelodysplasia, or multiple handicaps to determine correlation between continuity of care and patient satisfaction. Study encompassed 2 comprehensive and 3 specialty clinics in Cleveland, Ohio.

Survey of 1,146 patient visits in an urban $\mathrm{HMO}$ to determine correlation between choice of provider, continuity of provider, and satisfaction

Survey of 1,726 Kentucky medicaid patients, 404 of which had a diagnosis of asthma, examining correlation between continuity of care and satisfaction with provider communication and patient influence over treatment decisions
For 18-month period, both continuity scores and patient satisfaction were significantly higher in experimental group. Continuity measured by usual provider continuity index (UPC), sequential continuity index (SECON), and the ability of patients to name their provider

After $1 \mathrm{y}$, patients receiving care in continuity clinic were significantly more satisfied with care and rated care quality and quality of staff-patient interactions more highly than control patients. Continuity was not measured in either group, but the experimental clinic was designed to provide continuity of provider

Mothers in experimental group were more satisfied with several aspects of care, including relationship with providers, even though satisfaction with care was similar at start of study. Continuity was measured by determining number of mothers who could name their provider, $69 \%$ of experimental group and $33 \%$ of controls after $4 y$

Women assigned to the continuity team were significantly more satisfied with care. Patients not blinded to the study design, and continuity not measured in the 2 groups

Patient satisfaction improved significantly with the change. Continuity with assigned team was measured by chart review and improved from $47 \%$ to $69 \%$, but was measured only for 30 "high-utilization" patients

Higher continuity scores correlated with increased patient satisfaction in both study groups. Continuity measured by number of providers seen (NOP)

Continuity of care as measured by UPC worsened significantly after the move. 23 families were lost to follow-up after the move. Patient satisfaction did not change significantly

Continuity was significantly better in the family practice group as measured by SECON, the NOP seen, and the ability to identify their usual provider. There was no significant difference in satisfaction. Patients were not randomly assigned and the care models were different in ways other than interpersonal continuity

Continuity of care as measured by patient report of seeing a usual provider accounted for the largest portion of the association between source of care and satisfaction. This was true in both comprehensive care and specialty care clinics

Both choosing one's physician and seeing one's own physician for the evaluated visit correlated significantly with satisfaction with care

Continuity as rated by patients on a Likert scale was significantly correlated with satisfaction in both groups, but was particularly important for the group with asthma 


\begin{tabular}{|c|c|c|c|}
\hline $\begin{array}{l}\text { Study Method, Study, } \\
\text { and Publication Date }\end{array}$ & Setting & Findings* & $\begin{array}{l}\text { Quality of } \\
\text { Evidence }\end{array}$ \\
\hline \multicolumn{4}{|l|}{ Correlation (continued) } \\
\hline $\begin{array}{l}\text { Hjortdahl \& Laerum, } \\
1992^{40}\end{array}$ & $\begin{array}{l}\text { Survey of } 3,918 \text { Norwegian patients to exam- } \\
\text { ine relationship between continuity of care } \\
\text { and patient satisfaction with their office visit }\end{array}$ & $\begin{array}{l}\text { A personal doctor-patient relationship } \\
\text { increased satisfaction sevenfold and the } \\
\text { duration of that relationship had a weak, but } \\
\text { significant association with satisfaction }\end{array}$ & 7.0 \\
\hline Kingston, $1983^{59}$ & $\begin{array}{l}\text { Survey of } 292 \text { residents of a senior citizen } \\
\text { apartment complex in Michigan examining } \\
\text { determinants of loyalty to provider }\end{array}$ & $\begin{array}{l}\text { Patients with higher self-rated continuity were } \\
\text { less likely to express interest in finding a new } \\
\text { provider }\end{array}$ & 6.5 \\
\hline Breslau, $1982^{44}$ & $\begin{array}{l}\text { Home interviews of } 369 \text { families of children } \\
\text { with cystic fibrosis, cerebral palsy, myelodys- } \\
\text { plasia, or multiple handicaps compared with } \\
459 \text { families of nondisabled children. Study } \\
\text { was done to determine whether continuity } \\
\text { of care is more important for the disabled } \\
\text { group }\end{array}$ & $\begin{array}{l}\text { Continuity was significantly better in the non- } \\
\text { disabled group, which also included families } \\
\text { with lower average income, less education, } \\
\text { and a higher proportion of nonwhite race. } \\
\text { Continuity of care correlated significantly } \\
\text { more strongly with } 3 \text { elements of patient } \\
\text { satisfaction in the disabled group. Continuity } \\
\text { was evaluated by patient rating of degree to } \\
\text { which patients saw their usual provider }\end{array}$ & 6.5 \\
\hline Mainous et al, $2001^{55}$ & $\begin{array}{l}\text { Survey of } 418 \text { US patients and } 650 \text { UK patients } \\
\text { examining correlates with patients' trust in } \\
\text { their physicians }\end{array}$ & $\begin{array}{l}\text { Trust was related to the length of the doctor- } \\
\text { patient relationship, but not to measures of } \\
\text { continuity. Continuity was measured by the } \\
\text { patients' ability to identify a usual provider } \\
\text { and by UPC. US patients valued continuity } \\
\text { more highly than UK patients }\end{array}$ & 6.0 \\
\hline Roland et al, $1986^{45}$ & $\begin{array}{l}128 \text { patients in } 4 \text { general practices in Bristol, } \\
\text { England, were followed for } 2 \mathrm{y} \text {. Two practices } \\
\text { had patients assigned to the clinic, and in } \\
2 \text { the patients were assigned to individual } \\
\text { providers }\end{array}$ & $\begin{array}{l}\text { Patients assigned to individual providers had } \\
\text { significantly higher continuity as measured } \\
\text { by the most frequent provider continuity } \\
\text { index. They were also more likely to request } \\
\text { their own doctor, more willing to wait for an } \\
\text { appointment, and more likely to view their } \\
\text { doctor as a friend }\end{array}$ & 5.0 \\
\hline Baker, $1996^{60}$ & $\begin{array}{l}\text { Survey of } 75 \text { patients from } 126 \text { British general } \\
\text { practitioners in } 39 \text { practices to determine cor- } \\
\text { relates of patient satisfaction }\end{array}$ & $\begin{array}{l}\text { Smaller practices and use of personal list } \\
\text { assignments were associated with higher sat- } \\
\text { isfaction. Continuity was not measured other } \\
\text { than recording whether partial or complete } \\
\text { personal assignment lists were used }\end{array}$ & 5.0 \\
\hline $\begin{array}{l}\text { Freeman \& Richards, } \\
1993^{39}\end{array}$ & $\begin{array}{l}\text { Home interviews with } 111 \text { patients from } 3 \\
\text { general practices in England to determine } \\
\text { patient values regarding personal continuity } \\
\text { and to compare the responses from patients } \\
\text { in practices with personal assignment lists vs } \\
\text { combined lists }\end{array}$ & $\begin{array}{l}\text { Most patients prefer to see the same doctor, } \\
\text { but patients in personal list practices value } \\
\text { this more. Patients in combined list practices } \\
\text { were less willing to wait to see their usual } \\
\text { provider. Continuity as measured by UPC } \\
\text { increased with patient age in both groups }\end{array}$ & 4.5 \\
\hline Flynn, $1985^{38}$ & $\begin{array}{l}\text { Survey of } 61 \text { prenatal patients at a university } \\
\text { family practice residency in Missouri to deter- } \\
\text { mine association between provider continuity } \\
\text { and pregnancy outcome }\end{array}$ & $\begin{array}{l}\text { Continuity as measured by the continuity of } \\
\text { care index and presence of assigned physi- } \\
\text { cian at delivery ranked 8th of } 10 \text { attributes } \\
\text { in importance to patients and did not signifi- } \\
\text { cantly correlate with satisfaction }\end{array}$ & 4.0 \\
\hline Kearley et al, $2000^{54}$ & $\begin{array}{l}\text { Survey of } 996 \text { adult patients from } 18 \text { British } \\
\text { general practices to determine when patients } \\
\text { most value having a personal doctor-patient } \\
\text { relationship }\end{array}$ & $\begin{array}{l}\text { Continuity relationships were highly valued as } \\
\text { very important or extremely important by } \\
64 \% \text { of patients and most valued when seri- } \\
\text { ous illness, psychosocial problems, and fam- } \\
\text { ily issues were present }\end{array}$ & 3.5 \\
\hline
\end{tabular}

not measure patient satisfaction directly. ${ }^{39,45}$ A common weakness of these correlational studies is inconsistency in how patient satisfaction is measured. In 6 of the 12 studies, patient satisfaction was measured using a previously validated and standardized instrument. ${ }^{37,38,41,44,59,60}$ In 2 others, satisfaction is explicitly measured by a simple Likert scale or patient interview that had not been previously validated. ${ }^{40,43}$ The remaining 4 studies do not directly attempt to measure satisfaction, but instead address issues that might be considered proxies for satisfaction, such as the desire to change clinicians or the willingness to wait for an appointment. ${ }^{39,45,54,55}$ All these correlational studies except one show an association between at least one aspect of improved satisfaction and interpersonal continuity. The exception found no relationship between clinician continuity and satisfaction among prenatal patients at the University of Missouri. ${ }^{38}$

\section{DISCUSSION}

The available data suggest a consistent significant association between interpersonal continuity of care and 
patient satisfaction. All these studies, however, are limited by a set of problems that impair our ability to isolate and study interpersonal continuity of care as a variable. Most Western health care systems allow patients to choose their own physicians, making it difficult to assign patients randomly to different care models. In the absence of random assignment, it is difficult to tell whether continuity leads to satisfaction or satisfaction leads to continuity. In fact, it seems likely that causality is bidirectional. Perhaps a better understanding of interpersonal continuity may come from studies using continuity as the dependent rather than the independent variable in a prospective design. Such a study might examine newly enrolled patients and follow them as a cohort to see which ones become long-term patients in the practice. The differences between those who stay and those who leave could reveal important elements of interpersonal continuity of care.

Selection bias is also a challenge to continuity researchers. Will interpersonal continuity improve satisfaction for all patients or for only those who care enough about it to choose such a model of care? Many of the studies in this review have shown increased patient satisfaction in practices that promote a personal physician for each patient. This finding does not mean that patients who are not in such practices would be more satisfied if their care model were changed. A few studies have examined ways to improve interpersonal continuity in a practice. ${ }^{45,46,53,60-64}$ It would be useful to add preintervention and postintervention satisfaction surveys to such studies in the future. Although not always feasible, a randomized trial design remains an ideal method to examine the relationship between continuity of care and satisfaction, but the intervention in such a trial does not need to be patient assignment. Instead, the intervention could be measures taken by a practice to improve interpersonal continuity.

There are some important limitations in the method we used for this review. Each report in this review used a slightly different approach to how continuity was defined and measured. Although these approaches were similar and all attempted to address interpersonal continuity, these differing techniques make it difficult to generalize from one study to the next. Our evaluation of the quality of each study was limited to only 5 criteria and was subjective. Finally, there was considerable diversity from one study to the next in the characteristics of the patient population being studied, and articles were included in the review from several western countries. On the one hand, this might increase the validity of our conclusions, but such diversity may also mask differences that limit our ability to generalize from one study to the next.

The availability of electronic medical records is enhancing our ability to communicate information efficiently from one clinician to another. We are no longer as dependent as we once were on the knowledge of a personal physician for many of the tasks of informational continuity. Some authors have predicted the end of personal care as we move to team-based care in the office and hospitalist systems for inpatient care. ${ }^{32}$ It is therefore more important than ever to establish those aspects of personal care that may be of enduring value to our patients. This review suggests that interpersonal continuity in the doctor-patient relationship has importance to patients in the United States, Great Britain, Australia, and several other countries.

In 1991, Gayle Stephens wrote, "As we struggle to direct our own evolution, let us not be intimidated or enticed to give up our most indispensable ideal-personal medicine. The need for it will never become passé, although we must continue to learn what it means and how to do it." ${ }^{12}$ Research into continuity remains limited by differing definitions and measurement techniques, but evidence that interpersonal continuity matters to patients and their physicians is sufficient to warrant caution as our health care system continues to change. Many aspects of the traditional interpersonal model of care may be essential elements of the future rather than outdated characteristics of the past.

To read or post commentaries in response to this article, see it online at http://www.annfammed.org/cgi/content/full/2/5/445.

Key words: Continuity of patient care; primary health care; physicianpatient relations; patient satisfaction

Submitted April 30, 2003; submitted, revised, August 12, 2003; accepted September 5, 2003.

\section{References}

1. Saultz JW. Continuity of care. In: Saultz JW, ed. Textbook of Family Medicine. 1st ed. New York, NY: McGraw-Hill; 2000:52-77.

2. McWhinney IR. Principles of family medicine. In: McWhinney IR, ed. A Textbook of Family Medicine. 2nd ed. New York, NY: Oxford University Press; 1997:18-20.

3. Committee on the Future of Primary Care. Primary Care: America's Health in a New Era. 1st ed. Washington, DC: Institute of Medicine: National Academy of Sciences; 1996.

4. Hansen MF. Continuity of care in family practice. J Fam Pract. 1975;2:439-444.

5. Wall EM. Continuity of care and family medicine: definition, determinants, and relationship to outcome. J Fam Pract. 1981;13:655-664.

6. Banahan BF, Banahan BF I. Continuity as an attitudinal contract. J Fam Pract. 1981;12:767-768.

7. Freeman G, Hjortdahl P. What future for continuity of care in general practice? BMJ. 1997;314:1870-1873.

8. Freeman G. Continuity of care in general practice. a review and critique. Fam Pract. 1984;4:1192-1194.

9. Starfield B. Continuous confusion? Am J Public Health. 1980;70:117-119.

10. Hennen BK. Continuity of care in family practice: part I: dimensions of continuity. J Fam Pract. 1975;2:371-372. 
11. Saultz JW. Defining and measuring interpersonal continuity of care. Ann Fam Med. 2003;134-143.

12. Stephens GG. The best ideal in family practice. JABFP. 1991;4:223228.

13. Emanuel EJ, Dubler NN. Preserving the physician-patient relationship in the era of managed care. JAMA. 1995;273:323-329.

14. Flocke SA, Stange KC, Zyzanski SJ. The impact of insurance type and forced discontinuity on the delivery of primary care. J Fam Pract. 1997;45:129-135.

15. Kikano GE, Flocke SA, Gotler RS, Stange KC. 'My insurance changed': the negative effects of forced discontinuity of care. Fam Pract Manag. 2000;7:44-45.

16. Bagley B. Hospitals and the family physician. Am Fam Phys. 1998;58:336-339.

17. Fleming DM. Continuity of care: a concept revisited. Eur J Gen Pract. 2000;6:140-145.

18. Kahana E, Stange KC, Meehan R, Raff I. Forced disruption in continuity of primary care: the patients' perspective. Sociol Focus. 1997;30:177-187.

19. Kogan MD, Alexander GR, Teitelbaum MA, Jack BW, Kotelchuck M, Pappas $G$. The effect of gaps in health insurance on continuity of a regular source of care among pre-school aged children in the United States. JAMA. 1995;274:1429-1435.

20. Newbery P. Time to rethink continuity. Can Fam Phys. 2000;46:12481249.

21. Muir Gray JA. Patient satisfaction. In: Muir Gray JA, ed. EvidenceBased Healthcare. 1st ed. London, England: Harcourt Brace and Company; 1997:126-133.

22. Weyrauch KF. The personal knowledge of family physicians for their patients. Fam Med. 1994;26:452-455.

23. Hjortdahl P. Continuity of care-going out of style? Br J Gen Pract. 2001;51:699-700.

24. Pereira Gray DJ. The key to personal care. J R Coll Gen Pract. 1979;29:666-678.

25. Stephens GG. Clinical biographies: issues in longitudinal care. Cont Educ. $1985 ; 260-275$.

26. Rogers J, Curtis P. The concept and measurement of continuity in primary care. BMJ. 1980;70:122-127.

27. Shortell SM. Continuity of medical care: conceptualization and measurement. Med Care. 1976;14:377-391.

28. Geyman JP. Continuity of care in family practice: part 4. J Fam Pract. $1975 ; 2: 445-447$

29. McWhinney IR. Continuity of care in family practice. Part 2: implications of continuity. J Fam Pract. 1975;2:373-374.

30. Baker R. Will the future GP remain a personal doctor? Br J Gen Pract. 1997;47:831-834.

31. Lewis C. Does comprehensive care make a difference? What is the evidence? Amer J Dis Child. 1971;122:469-474.

32. Guthrie B, Wyke $S$. Does continuity in general practice really matter? BMJ. 2000;321:734-736.

33. Dietrich AJ, Marton KI. Does continuous care from a physician make a difference? J Fam Pract. 1982;15:929-937.

34. Miller C. Ensuring continuing care: styles and efficiency of the handover process. Austr J Adv Nursing. 1998;16:23-27.

35. Leopold N, Cooper J, Clancy C. Sustained partnership in primary care. J Fam Pract. 1996;42:129-137.

36. Reid R, Haggerty J, McKendry R. Defusing the Confusion: Concepts and Measures of Continuity of Health Care. Ottawa, Ontario: Canadian Health Services Research Foundation; 2002.

37. Breslau N, Mortimer EAJ. Seeing the same doctor: determinants of satisfaction of specialty care for disabled children. Med Care. 1981;19:741-758.

38. Flynn SP. Continuity of care during pregnancy: The effect of provider continuity on outcome. J Fam Pract. 1985;21:375-380.
39. Freeman GK, Richards SC. Is personal continuity of care compatible with free choice of doctor? Patients' views on seeing the same doctor. Br J Gen Pract. 1993;43:493-497.

40. Hjortdahl P, Laerum E. Continuity of care in general practice: effect on patient satisfaction. BMJ. 1992;304:1287-1290.

41. Love MM, Mainous III AG, Talbert JC, Hager GL. Continuity of care and the physician-patient relationship: the importance of continuity for adult patients with asthma. J Fam Pract. 2000;49:998-1004.

42. Shortell SM, Richardson WC, LoGerfo JP, et al. The relationships among dimensions of health services in two provider systems: a causal model approach. J Health Soc Behav. 1977;18:139-159.

43. Weyrauch KF. Does continuity of care increase HMO patients' satisfaction with physician performance? JABFP. 1996;9:31-36.

44. Breslau N. Continuity re-examined: differential impact on satisfaction with medical care for disabled and normal children. Med Care. 1982;20:347-360.

45. Roland M, Mayor V, Morris R. Factors associated with achieving continuity of care in general practice. J R Coll Gen Pract. 1986;36:102-104.

46. Smith CS. The impact of an ambulatory firm system on quality and continuity of care. Med Care. 1995;33:221-226.

47. Alpert JJ, Robertson LS, Kosa J, Haggerty MC, Haggerty RJ. Delivery of health care for children: report of an experiment. Pediatrics. 1976;57:917-930.

48. Becker MH, Drachman RH, Kirscht JP. A field experiment to evaluate various outcomes of continuity of physician care. Am J Public Health. 1974;64:1062-1070.

49. Becker MH, Drachman RH, Kirscht JP. Continuity of pediatrician: new support for an old shibboleth. J Pediatr. 1974;84:599-605.

50. Wasson JH, Sauvigne AE, Mogielnicki RP, et al. Continuity of outpatient medical care in elderly men: a randomized trial. JAMA. $1984 ; 252: 2413-2417$.

51. Schmittdiel J, Selby JV, Grumbach K, Quesenberry CP. Choice of a personal physician and patient satisfaction in a health maintenance organization. JAMA. 1997;278:1596-1599.

52. Shear CL, Gipe BT, Mattheis JK, Levy MR. Provider continuity and quality of medical care. Med Care. 1983;21:1204-1210.

53. Breslau N, Haug MR. Service delivery structure and continuity of care. J Health Soc Behav. 1976;17:339-352.

54. Kearley KE, Freeman GK, Heath A. An exploration of the value of the personal doctor-patient relationship in general practice. Br J Gen Pract. 2001;51:712-718.

55. Mainous AG III, Baker R, Love MM, Pereira Gray DJ, Gill JM. Continuity of care and trust in one's physician: evidence from primary care in the United States and the United Kingdom. Fam Med. 2001;33:22-27.

56. Hruby M, Pantilat SZ, Lo B. How do patients view the role of the primary care physician in inpatient care? Am J Med. 2001;111:21S-25S.

57. Alpert JJ, Kosa J, Haggerty RJ, Robertson LS, Heagarty MC. Attitude and satisfactions of low-income families receiving comprehensive pediatric care. Am J Public Health. 1970;60:499-506.

58. Rowley MJ, Hensley MJ, Brinsmead MW, Wlodarczyk JH. Continuity of care by a midwife team versus routine care during pregnancy and birth: a randomized trial. Med J Aust. 1995;163:289-293.

59. Kingston PO. Patient ties to ambulatory care providers: the concept of provider loyalty. Jour Health Care Marketing. 1983;3:27-34.

60. Baker R. Characteristics of practices, general practitioners, and patients related to levels of patients' satisfaction with consultations. $\mathrm{Br}$ J Gen Pract. 1996;46:601-605.

61. Kibbe DC, Bentz E, McLaughlin CP. Continuous quality improvement for continuity of care. J Fam Pract. 1993;36:304-308.

62. Neher JO, Kelsberg G, Oliveira D. Improving continuity by increasing clinic frequency in a residency setting. Fam Med. 2001;33:751-755.

63. Merenstein D, D'Amico F, Devine B, et al. Longitudinal versus traditional residencies: a study of continuity of care. Fam Med. 2001;33:746-750.

64. Retchin SM, Kerr K, White M, Blish C. Continuity of care after July. J Gen Intern Med. 1986;1:94-97. 